
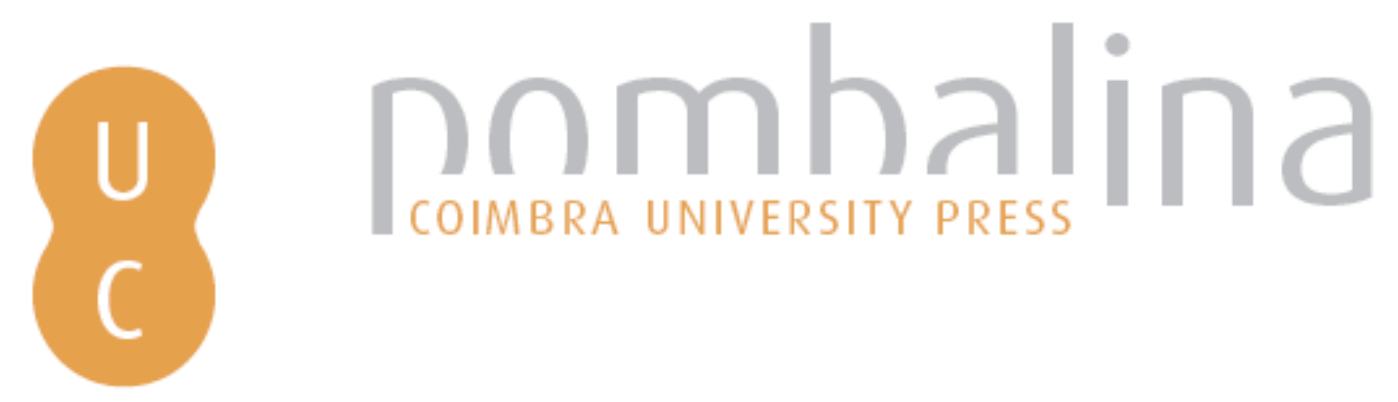

\title{
Vestigios de Valerio Flaco en El vellocino de oro de Lope de Vega
}

Autor(es): $\quad$ Torres-Murciano, Antonio Río

Publicado por: Centro de Estudos Clássicos e Humanísticos da Universidade de

URL

persistente: URI:http://hdl.handle.net/10316.2/30280

DOI: $\quad$ DOI:http://dx.doi.org/10.14195/978-989-721-038-9_51

Accessed : $\quad$ 26-Apr-2023 11:38:06

A navegação consulta e descarregamento dos títulos inseridos nas Bibliotecas Digitais UC Digitalis, UC Pombalina e UC Impactum, pressupõem a aceitação plena e sem reservas dos Termos e Condições de Uso destas Bibliotecas Digitais, disponíveis em https://digitalis.uc.pt/pt-pt/termos.

Conforme exposto nos referidos Termos e Condições de Uso, o descarregamento de títulos de acesso restrito requer uma licença válida de autorização devendo o utilizador aceder ao(s) documento(s) a partir de um endereço de IP da instituição detentora da supramencionada licença.

Ao utilizador é apenas permitido o descarregamento para uso pessoal, pelo que o emprego do(s) título(s) descarregado(s) para outro fim, designadamente comercial, carece de autorização do respetivo autor ou editor da obra.

Na medida em que todas as obras da UC Digitalis se encontram protegidas pelo Código do Direito de Autor e Direitos Conexos e demais legislação aplicável, toda a cópia, parcial ou total, deste documento, nos casos em que é legalmente admitida, deverá conter ou fazer-se acompanhar por este aviso. 


\section{De ayer a hoy}

\section{Influencias clásicas en la literatura}

\section{Aurora López, Andrés Pociña, Maria de Fátima Silva (coords.)}




\title{
Vestigios de Valerio Flaco en El Vellocino de oro de LOPE DE VEGA
}

\author{
Antonio Río Torres-Murciano \\ Universidad de Santiago de Compostela
}

\begin{abstract}
En El vellocino de oro de Lope de Vega se hallan algunas innovaciones introducidas en el mito de los argonautas por Valerio Flaco, como son la comparación de los trabajos de Hércules con la busca del vellocino y la aprobación dada a esta empresa por Júpiter frente a la reluctancia de los dioses del mar. Puesto que Lope no pudo haber recibido de otras fuentes antiguas estos elementos, que tampoco se encuentran en las compilaciones mitológicas al uso, es necesario concluir que los tomó directamente de Flaco, cuyo nombre había incluido en los índices de la Arcadia y del Isidro.
\end{abstract}

La comedia mitológica $E l$ vellocino de oro, pieza cortesana de Lope de Vega famosa por el incendio que, en mayo de 1622, interrumpió su estreno ante el rey Felipe IV en los jardines de Aranjuez ${ }^{1}$, se abre con un diálogo entre la Fama y la Envidia a lo largo del cual la segunda anuncia el objeto de la representación ${ }^{2}$ :

Aquella historia que canta

Ovidio, de donde tuvo

principio el Tusón de España.

(187-189)

La busca del vellocino de oro, posteriormente identificado con el Toisón de la insigne orden de caballería heredada de la Casa de Borgoña por los Austrias españoles, constituye uno de los mitos más recreados por la literatura

${ }^{1}$ Acerca de las características y circunstancias de la célebre representación, cf. M. Menéndez y Pelayo, Estudios sobre el teatro de Lope de Vega, vol. II (Obras completas, vol. XXX), Madrid, CSIC, 1949, pp. 212-226; J. M. Díez Borque, "Sobre el teatro cortesano de Lope de Vega: El vellocino de oro, comedia mitológica” en J. Canavaggio (ed.), La Comedia, Madrid, Casa de Velázquez, 1995, pp. 155-177 (159-164); T. Ferrer Valls, "El vellocino de oro y El amor enamorado en la producción dramática cortesana de Lope de Vega: las obras de madurez”, en J. Berbel et al. (eds.), En torno al teatro del Siglo de Oro. Actas de las XI-XIII Jornadas de Teatro del Siglo de Oro, Almería, Instituto de Estudios Almerienses, 1996, pp. 49-63 (50-51), J. A. Martínez Berbel, El mundo mitológico de Lope de Vega. Siete comedias de inspiración ovidiana, Granada, Universidad de Granada, 2002 <http://hdl.handle.net/10481/4414>, pp. 409-410, 506-509.

${ }^{2} \mathrm{El}$ texto de El vellocino de oro se cita por la edición digital de la Biblioteca Virtual Miguel de Cervantes (Alicante, 1999) <http://www.cervantesvirtual.com/FichaObra.html?Ref=888>, basada en la realizada para la Biblioteca de Autores Españoles por M. Menéndez y Pelayo (ed.), Obras de Lope de Vega, vol. XIV, Madrid, Atlas, 1966, pp. 102-133. 
grecorromana. ${ }^{3}$ Pero la mención explícita de Ovidio hizo que se identificara en la obra del Sulmonense (concretamente, en Metamorfosis VII 1-403, más que en Heroidas XII) la fuente principal, y quizás única, de la que se habría servido Lope para la redacción de su comedia. Esta era la tesis sostenida por Henry M. Martin en un casi centenario estudio que hasta tiempos muy recientes ha sido citado como autoridad ${ }^{4}$, en el que aseveraba, además, que no hallaba en $E l$ vellocino de oro rastro cierto de las Argonáuticas griegas de Apolonio de Rodas ni de las latinas de Valerio Flaco ${ }^{5}$.

Por cuanto respecta a Flaco, la afirmación de Martin nos parece discutible. Para empezar, resuenan claramente unos versos de las Argonáuticas romanas en el pasaje en el que el Jasón de Lope le repite a Fineo las engañadoras palabras con las que su tío Pelias le ha encomendado la búsqueda del vellocino ${ }^{6}$ :

Hércules tiene vencidas las difíciles empresas del mundo, en Europa y Asia; como la sierpe Lernea, el fiero león de Arcadia, y la calidonia fiera. Mató al gigante Aqueloo; y así, no queda que emprendas sino el vellocino de oro.

(1104-1112) sed neque bella videt Graias neque monstra per urbes

ulla: Cleonaeo iam tempora clausus biatu Alcides, olim Lernae defensus ab angue Arcas et ambobus iam cornua fracta iuvencis.

ira maris vastique placent discrimina ponti. (I 33-37)

En la comedia de Lope, el pérfido Pelias anima a Jasón a llevar a cabo la única gesta que las hazañas de Hércules han dejado a su alcance, siguiendo una reflexión análoga a la que llevaba al Pelias de Valerio Flaco a enviar a su odiado sobrino a la Cólquide, tras advertir que en Grecia no había posibilidad alguna de encargarle una empresa que le acarreara la muerte. Entre los trabajos de Hércules, el león de Nemea y la hidra de Lerna son mencionados tanto por Flaco como por Lope, cuya referencia al "gigante Aqueloo" podría proceder de la interpretación

${ }^{3}$ Dejando aparte obras parcial o totalmente perdidas como las Medeas de Enio, Acio, Ovidio y Lucano, contamos con las de Eurípides y Séneca, con la Pítica IV de Píndaro y con los dos poemas épicos de Apolonio de Rodas y de Valerio Flaco, fuentes a las que hay que sumar las noticias de los mitógrafos (Apollod., I 9.16-24; Hyg., Fab. III, XIV, XXI, XXII).

${ }^{4}$ Ex. gr. Díez Borque, op. cit. (n. 1), p. 172.

${ }^{5}$ H. M. Martin, "Lope de Vega's El vellocino de oro in relation to its sources", Modern Language Notes 39, 1924, pp. 142-149 (147). Acerca de la posible utilización de otras fuentes antiguas por Lope, cf. A. Pociña, "Tres dramatizaciones del tema de Medea en el Siglo de Oro español: Lope de Vega, Calderón de la Barca y Rojas Zorrilla”, en A. López y A. Pociña (eds.), Medeas. Versiones de un mito desde Grecia hasta hoy, vol. II, Granada, Universidad de Granada, 2002, pp. 751-777 (761-767). 1980).

${ }^{6}$ El texto de las Argonáuticas se cita por la edición teubneriana de W.-W. Ehlers (Stuttgart, 
que se suele dar a la vaga alusión valeriana a "los dos novillos" derrotados por el Tirintio ${ }^{7}$. Si, además, tenemos en cuenta que este curioso planteamiento del encargo de Pelias no se halla en ninguna otra fuente antigua conservada, razón por la cual ha sido generalmente atribuido a la inventiva de Valerio, deudora en este punto del prólogo del Hercules furens de Séneca ${ }^{8}$, cobra fuerza la hipótesis de la imitación directa, a la que hay, sin embargo, un argumento de peso que oponer. Porque, como bien ha demostrado Juan Antonio Martínez Berbel ${ }^{9}$, el texto seguido aquí por Lope es el de la libérrima traducción de las Metamorfosis de Ovidio realizada por Jorge de Bustamante ${ }^{10}$, quien, al igual que el Fénix, localiza al león de Nemea en Arcadia y atribuye a Hércules la caza del jabalí de Calidón, hazaña en la que no le concedían parte alguna los testimonios antiguos ${ }^{11}$. No parece, pues, descabellado suponer que, para amplificar la narración parcial que del mito de los argonautas había hecho Ovidio, se sirvió Bustamante de las Argonáuticas de Flaco, que pudo haber conocido cuando estudiaba en la Universidad Complutense ${ }^{12}$, y que de Bustamante recibió Lope la relación, originalmente valeriana, entre el mandato de Pelias y los trabajos de Hércules. La deuda de El vellocino de oro con la versión del cántabro es, por lo demás, tan evidente que ni siquiera parece dable afirmar que el Fénix se haya servido directamente del texto latino de las Metamorfosis ovidianas a la hora de redactar su comedia ${ }^{13}$. Pero, como se verá a continuación, pueden identificarse en esta

${ }^{7}$ De los ambo iuvenci (I 36) uno sería el toro de Creta (mejor que el Minotauro o el toro de Maratón, muertos por Teseo) y el otro el río Aqueloo, a quien Hércules rompió un cuerno (cf. Ov. Met. IX 85-86).

${ }^{8}$ En concreto, de los versos en que Juno mostraba su desesperación por no saber ya qué peligros idear contra su aborrecido hijastro Hércules, que había salido airoso de todas sus asechanzas (3074). El eco ha sido reconocido por todos los intérpretes del pasaje valeriano a partir de P. Langen C. Valeri Flacci Setini Balbi Argonauticon libri octo, Berlín, Calvary, 1896-1897, p. 23.

${ }^{9}$ Op. cit. (n. 1), pp. 478-482.

${ }^{10}$ En adelante, se seguirá al citar esta obra la paginación de la edición de 1595 (Las Transformaciones de Ovidio en lengua española, repartidas en quinze libros, con las Allegorias al fin dellos, y sus figuras, para provecho de los Artifices, Amberes, Pedro Bellero). Acerca de la primera edición, aparecida hacia 1540 sin indicación de autor, impresor, fecha ni lugar, cf. L. Carrasco Reija, "La traducción de las Metamorfosis de Ovidio por Jorge de Bustamante", en J. M. Maestre Maestre et al. (eds.), Humanismo y pervivencia del mundo clásico II. Homenaje al profesor Luis Gil, vol. II, Cádiz, Universidad de Cádiz - Ayuntamiento de Alcañiz, pp. 987-994 (987-988).

11 "Porque las marauillosas y grandes cosas que darte gloria de vencedor pudiessen, como fue el leon de Arcadia el puerco de Calidonia, la serpiente Lernea el gigante Acheloo, todo lo ha vencido y sojuzgado Hercules, y no queda ya cosa ninguna tan señalada como estas para que tu ahora emprendas, sino tan sola vna que en este punto me ha venido a la memoria en la qual si tu essa tu osada ynuencible y fuerte persona osas auenturar, venciendola saldras el mas afamado y victorioso hombre del mundo: porque es la conquista del velocino de oro, que en la ysla de Colcos esta" (p. 98a).

${ }^{12}$ Acerca del paso de Bustamante por las aulas de Alcalá, donde publicó en 1524 el maestro Lorenzo Balbo de Lillo la primera edición española de las Argonáuticas latinas, cf. M. Menéndez y Pelayo, Biblioteca de traductores españoles, vol. I (Obras completas, vol. LIV), Madrid, CSIC, 1952-1953, p. 258; Carrasco Reija, op. cit. (n. 10), p. 987.

${ }_{13}$ Martínez Berbel, op. cit. (n. 1), p. 444. 
vestigios valerianos que no se hallan en la obra de Bustamante, ni tampoco en los repertorios y compilaciones que circulaban en la época ${ }^{14}$.

Mientras que el Jasón de Bustamante aceptaba con ingenuo entusiasmo la incitación de Pelias a la aventura ${ }^{15}$, el de Lope parte, como el de Flaco, a pesar de haber adivinado las malvadas intenciones de su tío:

Y puesto que vi su envidia, no quise que conociera, ni en mi valor cobardía, ni en sus intentos bajeza. $(1120-1123)$
Mox taciti patuere doli nec vellera curae esse viro, sed sese odiis immania cogi in freta.

(I 64-66)

Poco antes de que el héroe de Lope supere las pruebas que le granjearán el vellón de oro, se le aparece el dios Marte ${ }^{16}$ para vaticinarle el éxito de una gesta que cuenta con el soberano beneplácito de Júpiter, así como el futuro catasterismo de la nave $\mathrm{Argo}^{17}$. Las concomitancias con Valerio Flaco son, una vez más, llamativas:

${ }^{14}$ Nada se encuentra al respecto en las Genealogiae deorum de Boccaccio, en la Officina de Ravisius Textor, en la Mythologia de Natale Conti o en el Dictionarium de Carolus Stephanus.

15 "Oydas por Iason estas no pesadas nueuas, luego accepto la empresa y partido de la presencia del tio desseoso de mostrar su bastante persona en tan gran cosa...” (p. 98b).

${ }^{16} \mathrm{E} 1$ dios Marte, que en el mito tenía un papel secundario por haberle sido consagrado el vellocino, había sido introducido en la narración como personaje por Valerio, que lo presentaba como enemigo de los argonautas. Pero el Marte magnánimo de Lope procede directamente, como ha señalado Martínez Berbel, op. cit. (n. 1), p. 456, del de Bustamante, que acogía con benevolencia a los hermanos Frixo y Hele después de que hubieran huido de las asechanzas de su madrastra a lomos del carnero de vellón de oro: "Frixo en llegando a esta ysla luego consagro el carnero al Dios Marte; al qual esta oblacion y sacrificio fue grata y muy acepta: y con admirable majestad y alegria baxo del cielo a la tierra a recebirle con graciosa y afable cara" (p. 97b).

${ }_{17}$ Mientras que, para Apolonio de Rodas, la Argo es solamente una nave especialmente renombrada, Flaco la presenta desde el comienzo de su poema como la primera que franqueó los mares (prima deum magnis canimus freta pervia natis, I 1), hazaña por la que mereció ser transformada en constelación (Alammifero tandem consedit Olympo, I 4). Bustamante alude a la prioridad de la nave de los argonautas en la historia de la navegación ("esta dizen que fue la primera que començo a andar sobre las aguas, p. 98b), pero no menciona el catasterismo evocado repetidamente por Valerio (I 303-304, IV 692-693, V 294-295). 
La invención de la nave Pegasea

Júpiter te agradece, $\mathrm{y}$ ha mandado que con cuarenta y cinco estrellas sea imagen en el círculo dorado, y que de la bellísima Medea tengas favor contra el dragón alado y los toros de fuego, pues al hielo de su desdén te dio favor el cielo. (2006-2013) deus haec, deus omine dextro

imperat; ipse suo voluit commercia mundo

Iuppiter et tantos hominum miscere labores. (I 245-247)

inde meae quercus tripodesque animaeque parentum

hanc pelago misere manum. via facta per undas

perque hiemes, Bellona, tibi.

(I 544-546)

El patrocinio prestado por Júpiter a la empresa de los argonautas, entendida como heroica apertura del tráfico marítimo y comienzo de las guerras entre Asia y Europa, constituye una invención original de Valerio, aventurada por Jasón en el primero de los pasajes citados y confirmada por el propio dios en el segundo. Y, tanto en Lope como en Flaco, la actitud favorable del dios supremo se opone a la de los indignados númenes del mar, quienes, reunidos en consejo, rechazan la navegación como si se tratara de una irrupción sacrílega en sus dominios ${ }^{18}$ :

En los palacios, sobre blanda arena, de perlas y corales fabricados, al Rey que el proceloso mar enfrena, ¡oh, hermanos, cuanto hermosos,

envidiosa propuso una sirena, [desdichados!, y a los marinos dioses convocados, que os diese el agua eterna sepultura; así trata la envidia a la hermosura.

Ese animal dorado pretendía que fuese a su deidad sacrificado sobre fuego del ámbar que el mar por atrevido a su cristal sagrado. [cría,
Heu quaenam aspicio? nostris modo concitus ausis aequoreos vocat ecce deos Neptunus et ingens concilium. fremere et legem defendere cuncti bortantur. (I 211-214)

${ }^{18}$ En Lope, la indignación de la sirena se debe a la incursión en sus aguas del carnero que porta a Frixo y a Helenia, atrevimiento que precede (y, en cierto modo, preludia) la travesía de la Argo, objeto de la cólera de Neptuno en Flaco. El concepto pesimista de la ilicitud de la navegación se halla ya en Horacio (Carm. I 3, 21 ss.) y en Séneca (Med. 301 ss., 595 ss.), pero es genuinamente valeriana la idea de reunir al comienzo del relato a las deidades marinas en un concilio análogo a aquellos que, desde Homero, solían tener lugar entre los olímpicos, tal como le recuerdan al lector los ilustres precedentes evocados por el pasaje (Verg., Aen. X 2, 9697; Ov., Met. I 167-252). Cf. A. Zissos, Valerius Flaccus' Argonautica, Book I. A Commentary, Oxford, OUP, 2008, pp. 191-193; S. Romano Martín, El tópico grecolatino del concilio de los dioses, Hildesheim, Olms, 2009, pp. 306-311. 
En la idea de que el viaje de los griegos a la Cólquide inauguraba los conflictos intercontinentales que habrían de culminar con la guerra de Troya, Valerio había presentado el rapto voluntario de Medea como preludio del de Helena, enfatizando una analogía de cuño herodoteo ${ }^{19}$ que, retomada por Lope con una despreocupada inversión cronológica, ha llamado en El vellocino de oro la reiterada atención de Martínez Berbel ${ }^{20}$ :

Medea, cuya hermosura es de aqueste reino Elena, no para incendios de Troya, ni para infamias de Grecia. (1056-1059)

Temiendo que la deshonra suceda a Colcos que a Grecia, siendo yo Elena, y él Troya. (1663-1665)

¡Fieras, aquí moriréis, que me da favor y esfuerzo la nueva Elena, que a Grecia, no a Troya, en mis naves llevo! (2042-2045)

\author{
nec vellera tantum \\ indignanda manent propiorque ex virgine \\ rapta \\ ille dolor, sed -nulla magis sententia menti \\ fixa meae-veniet Phrygia iam pastor ab \\ $I d a$, \\ qui gemitus irasque pares et mutua Grais \\ dona ferat. quae classe debinc effusa \\ procorum \\ bella, quot ad Troiae flentes biberna \\ Mycenas, \\ quot proceres natosque deum, quae robora \\ cernes \\ oppetere et magnis Asiam concedere fatis! \\ (I 546-554)
}

quemque suas sinat ire domos nec Marte

cruento

Europam atque Asiam prima haec

committat Erinys.

namque datum hoc fatis trepidus

supplexque canebat

Mopsus, ut in seros irent magis ista nepotes

atque alius lueret tam dira incendia raptor.

(VIII 395-399)

Los ecos hasta aquí señalados, a los que quizás podría añadirse algún otro, ${ }^{21}$ delatan la presencia en El vellocino de oro de algunas de las más peculiares

${ }^{19}$ Mientras que Heródoto (I 1-4), al plantear la archaeologia de las guerras médicas como una pugna entre Europa y Asia sustanciada en una serie de raptos recíprocos (Ío, Europa, Medea y Helena), realiza una lectura racionalista del mito, que seguirá Licofrón (Alex. 1291 ss.), Valerio, que reduce la cadena a los dos únicos eslabones que le interesan (Medea y Helena), refuerza la naturaleza literaria del viejo relato, de acuerdo con un diseño que será imitado por Estacio (Ach. II 72-79). Cf. A. Río Torres-Murciano, "El designio de Júpiter en Valerio Flaco. Providencia, historia y tradición literaria”, CFC. ELat 30, 2010, pp. 131-163 (141-142).

${ }^{20}$ Op. cit. (n. 1), pp. 475, 495, 503-504, 514.

${ }^{21}$ El rapto final de las colcas por los argonautas (2148-2157), que justamente han señalado 
innovaciones introducidas en la leyenda de Jasón por Valerio Flaco, cuyas Argonáuticas (al menos el libro I, y probablemente también el VIII) deben, pues, contarse entre las lecturas que se dieron cita en la mente de Lope cuando componía este drama. Y no es de extrañar, puesto que ya antes había incluido en los índices de dos de sus obras más ambiciosas el nombre del épico flavio ${ }^{22}$, cuyo retrato había tenido a bien instalar, junto con los de los demás épicos posvirgilianos, en el fabuloso palacio de la Poesía que se describe en el libro V de la Arcadia $^{23}$ :

Atentamente miraban los pastores la guarnecida sala de aquel palacio, no de diversas labores ni ricas sedas, sino de solos cuadros de parecidos retratos de poetas famosos y de algunas epigramas, debajo de los cuales estaba la Envidia entre Zoilo y Aristarco, tan vivos que parece que decían que Ovidio era lascivo, Estacio duro, congojoso e hinchado, Silio Itálico vulgar y humilde, y Valerio Flaco y Lucano más atrevidos que graves.

como hallazgo de Lope tanto Martínez Berbel, op. cit. (n. 1), p. 497, como Pociña, op. cit. (n. 5), p. 767, podría estar inspirado en los versos valerianos que narran los reproches hechos a Jasón por Eetes (cur age non templis sacrata avellere dona / omnibus atque ipsas gremiis abducere natas, I praedo, libet?, VII 48-50), o en los que recogen el lamento de la madre de Medea (Aesonide, non hoc Pelias evadere furto / te iubet aut ullas Colchis abducere natas, VIII 155-156).

${ }^{22} \mathrm{El}$ autor de las Argonáuticas romanas comparece en no menos de tres ocasiones (s.v. Argos, Jasón, Valerio Flaco) en la "Exposición de los nombres poéticos y históricos" que acompaña a la Arcadia (Madrid, 1598), así como en la lista de "Los libros y autores que se citan para la exornación de esta historia" con la que se ilustra el Isidro (Madrid, 1599). Cf. E. S. Morby (ed.). Lope de Vega: La Arcadia, Madrid, Castalia, 1975, pp. 68 n. 29, 293 n. 131, 422 n. 124; A. Sánchez Jiménez (ed.), Lope de Vega: Isidro, Madrid, Cátedra, 2010, p. 650. Hay que reconocer, empero, que Lope no cita a Flaco en las notas del Isidro ni en las de la Jerusalén conquistada, mientras que sí menciona en las unas y en las otras a Silio Itálico y a Estacio. Cf. A. K. Jameson, "Lope de Vega's Knowledge of Classical Sources", Bulletin Hispanique 38, 1936, pp. 444-501 (466-467, 470-472).

${ }^{23} \mathrm{El}$ texto de la Arcadia se cita por la edición de Morby, op. cit. (n. 20), p. 422. 